\title{
TAHSP:-
}

The Internet Joưnal of Allied Health Sciences and Practice

A Peer Reviewed Publication of the College of Health Care Sciences at Nova Southeastern University

Dedicated to allied health professional practice and education

http://ijahsp.nova.edu Vol. 11 No. 4 ISSN 1540-580X

\section{Participatory Action Research to Determine Essential Elements of a Wheelchair Assessment}

\author{
Teresa Plummer, PhD, OTR, ATP, CEAS, CAPS ${ }^{1}$ \\ Max Ito, PhD, OTR2 \\ Ferol Ludwig, PhD, OTR, FAOTA, GCG 3
}

1. Assistant Professor, Belmont University, Nashville, Tennessee

2. Associate Professor, Nova Southeastern University, Fort Lauderdale, Florida

3. Professor Emerita, Nova Southeastern University, Fort Lauderdale, Florida

United States

CITATION: Plummer T, Ito M, Ludwig F. Participatory Action Research to Determine Essential Elements of a Wheelchair Assessment. The Internet Journal of Allied Health Sciences and Practice. Oct 2013. Volume 11 Number 4.

\section{ABSTRACT}

Nearly 3 million people in the Unites States utilize a wheelchair for mobility. Yet, there is no standardized assessment or procurement process for wheelchair provision. Thus, practitioners have limited guidance in the essential elements of a wheelchair assessment. End users may have no or limited experience in determining the best choice of wheelchairs to meet their needs and often rely on the knowledge of the practitioner in the decision-making process of wheelchair selection. The author explored the current state of practice and the essential elements in the wheelchair assessment and procurement process. Obtaining the correct wheelchair is a complex process, involving the client, family, practitioners, suppliers, manufacturers, policy makers and insurers. This study utilized a qualitative research approach using Participatory Action Research (PAR) and a Delphi consensus approach to garner input from 155 individuals who have experience in or with wheelchair assessments. Participants in this study included representation from wheelchair manufacturers, suppliers, educators, occupational and physical therapists, end users, policy makers, and government affairs personnel. The findings of this study suggest that the wheelchair assessment include a wide range of elements, be client specific, and reflect a client-centered process.

\section{INTRODUCTION / STATEMENT OF THE PROBLEM}

According to the U.S. Census Bureau's Survey of Income and Program Participation (SIPP), an estimated 2.8 million. Americans residing outside of institutions utilize wheelchairs as an assistive technology device for mobility impairments. ${ }^{1}$ There are 51 million people with disabilities; people who use mobility devices make up $1 \%$ of the population aged 6 and older. ${ }^{1}$ Obtaining the correct wheelchair is a complex process, and if one is unable to obtain the correct wheelchair, it may lead to untoward consequences of injury, contribute to activity limitations, and may impact one's ability to be employed. Unfortunately, there is no consistent measurement standard or procedure for the practitioner who prescribes a mobility device.

While the potential benefit of assistive technology (AT) is known to consumers, caregivers, health-care practitioners, and policy makers, there is limited empirical evidence to validate the benefit and efficacy of wheelchair provision.,2,3 The AT community would benefit from a developed standard of practice for wheelchair assessment because the potential benefit of wheeled mobility devices cannot be determined without an assessment of a client's functional and medical status and desired goals.-9

In the 2003 State of Science report regarding wheelchair seating, the clinician's task force summarized the current priority, stating that the "associated tools, products, and evaluation methods must be developed in order to standardize and improve the 
diagnostic and prognostic value of seating evaluations," and that "presently, a standardized protocol for wheelchair seating and positioning evaluation is nonexistent." ${ }^{5}$ In describing the current practice, they conclude that seated posture and function are largely determined non-systematically through observation based on methods defined by individual practice sites. While these measurements may be helpful, they do not always help the practitioner determine the most appropriate device or related mobility goals. For example, a client might state that she wants a lightweight chair that folds, but this information alone is not enough to help the practitioner identify the specific wheelchair she needs.

Rapid advancement of wheelchair technology, funding priorities, and demands for evidence-based practice have all complicated the wheelchair procurement process. ${ }^{10}$ Evidence-based practice requires that practitioners use formal, objective measurements to guide practice. ${ }^{11}$ Prescribing an appropriate mobility device for a client requires a clinician to stay informed about technological advancement, balance reimbursement, and productivity management issues, and to accurately assess the client's needs and goals and involve them in the decision-making process. In Sweden, Wressle and Samuelsson examined user satisfaction with mobility devices and found that $22 \%$ of the respondents believed that their needs and demands were not adequately considered during the wheelchair assessment process. ${ }^{12}$

Wressle and Samuelsson's study further illustrates that the wheelchair assessment and procurement process is complicated. ${ }^{12}$ Practitioners must make a recommendation that reflects the client's preferences, environmental constraints, and the reimbursement and funding guidelines for each individual client. ${ }^{10-11}$ The final choice of wheelchair and seating systems often represents a compromise, meeting some of the client's goals, addressing environmental and reimbursement constraints, and making the best choice of technology. ${ }^{13}$

At present, there are a significant number of potential barriers to assessment and procurement for wheeled devices. These barriers include public policies, funding, practitioner and end user knowledge or lack thereof, and advocacy for and by people with disabilities. ${ }^{14-18}$ Potential AT users also confront various levels of barriers in the procurement of devices. These issues include appropriate referrals and funding for the recommended devices. ${ }^{14}$ Additionally, Carey et al. state that financing and accessing AT is a fundamental problem exacerbated by race, ethnicity, and cultural differences. ${ }^{14}$ Other findings conclude that health care professionals lack knowledge about AT; some do not know how to make appropriate recommendations for the specific device, how to document a patient's needs, how to advocate for AT, or how to initiate the funding and appeals processes for third party payer requirements. ${ }^{15}$

In fact, research consistently identifies funding as a major barrier in obtaining AT devices. ${ }^{15-18}$ The lack of financing for AT devices is directly linked, not only to economic oppression, but also to societal oppression. ${ }^{19}$ People with disabilities do not have access to the appropriate resources to be able to attend school, become employed, pursue leisure interests, or access that same level of information that able-bodied individuals can.20-21

Because AT devices facilitate both quality of life and psychosocial and functional health, a lack of access or inappropriate devices can negatively affect one's health.,20-21-25 Lack of trained personnel, inadequacies of a comprehensive assessment, and policies that fail to consider consumer preference are also potential barriers to health and quality of life. ${ }^{8}$

In summary, the wheelchair assessment and procurement process is complex and not well researched, but the need to consider client choice and values is well documented. There are also multiple levels of procedural, political, and funding issues that further contribute to the multiplicity of issues that affect the wheelchair assessment and procurement process. In conclusion, a need for a systematic and detailed review of the perspectives of all stakeholders involved may contribute to a greater understanding and perhaps an improved process of meeting the needs of wheeled mobility users.

\section{PURPOSE OF THE STUDY}

The purpose of this action research study was to examine the current state of practice in the wheelchair assessment and procurement process by garnering input from various stakeholders. Additionally, this study sought to obtain consensus on the essential elements that should be included in a wheelchair assessment based on stakeholder input. In this study, stakeholders included clients who use wheelchairs or end users, manufacturers of wheelchairs and related components, clinicians who evaluate end users, suppliers who assist in the procurement of wheelchairs, individuals who educate suppliers and clinicians, reimbursement reviewers, and other individuals such as government affairs officials who examine funding. 


\section{REVIEW OF THE LITERATURE}

\section{Disability from the Perspective of the Client}

Lutz and Bowers conducted a qualitative study of people with disabilities to determine what factors helped them to integrate their disability into everyday life. They conducted 21 Internet interviews, 17 in-person interviews, biographical accounts of four texts written by people with disabilities, and one anthology from 205 women with spinal cord injuries. They found that the "degree to which people integrate disabilities into their life was related to three factors: (a) the fundamental effects of the disabling condition, (b) others' perceptions of disability and its influence, and (c) the need for and use of multiple resources."26 In the findings of Lutz and Bowers, "resources were indicated to be the most critical factor in how well people with disabilities were able to integrate the experience of disability into their lives."26 Participants described necessary resources, among other things, as emotional support, Assistive Technology, and health care. Additionally, they specifically mention that when services are rendered by individuals who are "trustworthy, respectful, and willing to collaborate and communicate," it helps integrate their disability into everyday life."26 The findings of this qualitative study provide subjective accounts from people with disabilities that highlight the need for adequate and appropriate resources delivered by trustworthy, respecting, health care providers. The study stresses that to understand disability, one must take into account the subjective experience of the individual; in other words, one must represent the perspective of the client. Finally, this study highlights the need for appropriate resources, particularly mobility devices, and substantiates the need for client- centered practice in wheelchair provision. ${ }^{26}$

\section{Wheelchair Assessment}

Using three focus groups of occupational therapists, Angelo et al sought to identify the best practice in occupational therapy AT evaluations, and four themes emerged. ${ }^{27}$ The focus groups agreed that the best practice was1) a client-centered approach, 2) the occupational therapists' evaluation should be comprehensive and include clinical trials, 3) the evaluation should include input from the client, family and caregivers, and 4) the secondary issue should be the funding source. In summary, the three focus groups each identified the top emerging priorities as 1) evaluations must be comprehensive, 2) the evaluator should know the consumers' present and future goals, and 3) the evaluation should consider performance and environmental contexts. While this study attempted to determine the best occupational therapy (OT) practice, it is not prescriptive in its attempt to define the elements of wheelchair evaluations. It does, however, support the need for a comprehensive, client-centered assessment. ${ }^{27}$

Isaacson also sought to identify the best practice guidelines for AT, specifically for seating and mobility evaluations. ${ }^{28}$ Using a Delphi technique, she garnered input from 15 occupational therapists and physical therapists that considered themselves experts in seating and mobility evaluations. The participants confirmed that seating evaluations are complex and require input from a therapist with experience, knowledge, and a desire for life-long learning and specialized skills. While identifying some general themes of practice, Isaacson's work does not suggest practice guidelines. She does, however, suggest that further research commence to determine the consumer's perspective and that such research be conducted by occupational or physical therapists. ${ }^{28}$

While assistive technology professionals may embrace a client-centered perspective, this philosophy has not been well documented in the provision of mobility devices. The AT community has not developed a standardized wheelchair assessment, though many authors have identified the need for such. The development of a wheelchair assessment requires the input of multiple stakeholders whose charge is to identify the current state of practice in the wheelchair assessment and procurement process and identify the essential elements of wheelchair assessment

\section{RESEARCH DESIGN AND METHODOLOGY}

This study utilized Participatory Action Research (PAR), which focuses on the empowerment of individuals through participation in research. ${ }^{29}$ PAR is a collaborative and consensual approach to inquiry that seeks to involve all stakeholders. Stringer defines action research as collaborative, systematic, and rigorous inquiry that allows researchers to investigate issues in diverse contexts to define problems and discover solutions. Action research aims to provide opportunities for disparate groups of people to engage in a consensual approach to inquiry. PAR, by design, links groups of people who are potentially in conflict so they may attain a viable, sustainable and effective solution to the problems they identify. ${ }^{30}$ Because the stakeholders involved in the wheelchair assessment and procurement process represent diversity and disparity in power (e.g., therapist and client, supplier and insurer) it is instructive to utilize a research approach aimed at consensus and anonymity, such as PAR.

As with all studies involving human subjects, Institutional Review Board approval was secured and informed consent forms were completed. Confidentiality was maintained by coding the response forms. Only the primary investigator / facilitator had access to the names of the participants. 
Potential participants included all stakeholders in the wheelchair assessment and procurement process including end users, practitioners, suppliers, manufacturers, educators, government affairs personnel, and insurers. Recruitment of participants was conducted by electronic solicitation and postings on various websites. Participants represented a snowball sampling or purposive sampling of stakeholders who are knowledgeable of the current state of wheelchair assessment and procurement. All participants were required to have at least one year of experience in the wheelchair assessment process, or for end users, have had a wheelchair for a period of one year or more. All participants must have had access to the Internet and be able to read and understand English fluently. Because data were collected via electronic communication, individuals were asked to communicate in writing. This method was chosen to allow for multiple data collection points across many time zones and over an extended period of time. Data collection began in June 2009 and ended in May 2010.

\section{DATA COLLECTION PROCEDURES}

Data collection procedures primarily involved electronic submissions for the three survey questions though utilized additional focus groups for practitioners and end users. Several telephone or personal interviews were conducted if the participant preferred this method of data collection. PAR does not dictate specific methods; rather, methods and data collection procedures are chosen to match the needs of the participants. Thus, data collection procedures varied in this study.

The Delphi is a group's process whose goal is to reach consensus. ${ }^{31}$ Consensus is obtained by utilizing several rounds of data collection with examination of the data occurring during and in-between each round of data collection. There is no agreed upon number of rounds in the Delphi methodology. However, several authors suggest three separate rounds of data collection. $30-33$ Action research authors, Stringer, and Kemmis and Taggart, suggest that PAR begins with open dialogue concerning the problem. ${ }^{30,34}$ Thus, the first electronic-generated data collection point for this study posed the question, "What are the strengths of the current wheelchair assessment and procurement practice?" The second question was, "What are the limitations of the current wheelchair assessment and procurement process?" and the third questions asked, "What are the essential elements of the wheelchair assessment?" For all questions, the researcher compiled the responses and returned the aggregate list to the participants to obtain consensus. However, due to a small sample size of end users and government and insurance representatives, consensus was not solicited from these two groups. This paper will primarily present the findings of the later question: "What are the essential elements of the wheelchair assessment and procurement process?" For a comprehensive review of the findings see the Tables 1 to 4 .

A brief review of the strengths and limitations of the wheelchair assessment follows to illustrate the consistency of the findings from all participants. And finally, this author, representing the compiled findings of this group, offers a suggested assessment checklist.

\section{Strengths of the Wheelchair Assessment}

A total of 59 practitioners representing 21 states, one general region of the United States, as well as Australia responded to the initial compilation of strengths and limitations related to the wheelchair assessment and procurement process. Practitioners completed on-line surveys and participated in focus groups. Practitioners involved in the online data collection phase of the study included 6 representatives from manufacturers of wheelchairs or components, 13 occupational therapists, 18 physical therapists, 14 suppliers, and 8 others. The submissions were coded using Nvivo 8 software with 39 themes emerging. ${ }^{35}$ The compiled list was sent to the practitioners to determine level of agreement. Thirty-seven practitioners or $63 \%$ of the total number of practitioners determined their agreement with the list of strengths and limitations. Of the 39 original themes, consensus of $75 \%$ was achieved for 23 of the items.

To briefly summarize the strengths of the assessment, practitioners agree that the wheelchair assessment should be conducted by a qualified and knowledgeable team of practitioners, be a comprehensive evaluation of a client's skills, including a mat evaluation, focus on the client's need or performance, and include justification on equipment selection with an emphasis on the match of the technology to the client.

A focus group was conducted with interested practitioners during the 2009 RESNA annual conference. An overview of the current status of the project was presented to the group of 13 practitioners, and 11 of the 13 agreed to contribute their comments to the study. Consistent with the input of the on-line practitioner group, the RESNA focus group members stated the strength of a wheelchair assessment is one that is comprehensive, utilizes a team approach, includes a mat evaluation completed by a therapis, and is client centered. It should be noted that these attendees are considered experts in this practice area, yet are in agreement with the practitioners (many of whom are specialist in this area of practice). That is, the assessment process should be a comprehensive, client-centered evaluation conducted by a qualified team and should include a mat evaluation performed by a therapist.

(c) The Internet Journal of Allied Health Sciences and Practice, 2013 
Recruitment of end users was sought by posting a letter of invitation on several Internet sites known to represent wheelchair users. Fourteen end users agreed to participate in the multiple rounds of data collection. Further, the researcher conducted focus groups with 14 additional wheelchair users at two rehabilitation centers in the southeast. The Delphi method was not used in data analysis of end user information as data collection occurred on one occasion. End users identified several themes that were consistent with the practitioners and included accurate measurements, consideration of a client's activities and lifestyle, knowledgeable practitioners who advocate for the needs of the client, and consideration of funding. However, end users stated that a comprehensive assessment should include pressure mapping, while only $8 \%$ of the practitioners stated the same. Nearly $50 \%$ of the end user groups had a diagnosis of spinal cord injury, which may have influenced their perception of pressure mapping. In fact, several individuals in the focus group reported that they recently had a wheelchair assessment that include pressure mapping. Consistent with practitioners, end users stated that the assessment should consider the client (specifically the client's activities and lifestyle), be conducted by a qualified and knowledgeable practitioner, and be client-centered (advocates for the needs of the client). End users differ in their inclusion of funding and pressure mapping as strengths or limitations.

A total of 5 individuals represented the "other stakeholder group." This group was comprised of insurance reviewers, government affairs representatives, and a Medical Director of a large government-owned research and rehabilitation center that participated either in an online electronic posting or a telephone interview and were asked to comment on the strengths and limitations of the wheelchair assessment and procurement process. This group identified themes similar to the practitioners and the end users. The stakeholder group stated that the assessment and procurement process included a systematic and team approach and an accurate and in-person assessment of the client. Additionally, they stated that the assessment should educate the end user, describe the current equipment, justify the recommended equipment, and include communication regarding funding. Practitioners or end users did not mention these later of these specific themes.

\section{Limitations of the Wheelchair Assessment}

In addition to collecting data on the strengths of a wheelchair assessment, the researcher asked the participants to comment on the limitations of a wheelchair assessment. Consensus was obtained on 11 items for the practitioner group. The themes included insurance regulations, policies, lack of reimbursement for services, dealer's time, and funding for equipment. Additionally, the practitioner group identified a lack of experienced clinicians, untrained reviewers, lack of consistency in the assessment process, excessive time between the evaluation and the deliver, and inappropriate equipment recommended prior to the current evaluation as limitations in the assessment process. The RESNA focus group noted similar limitations such as a lack of funding, inconsistency in the process, lack of practice guidelines, insufficient time to complete a thorough evaluation, and lack of time to confront denials. These limitations are consistent with findings from previous research. $4-5,7-10,14,16-17,19$

Additionally, the RESNA practitioner focus group stated that end users participation in the assessment process is not optimal and that the lack of support for the Assistive Technology Professional credential by OT and PT associations is a limitation.

End users noted that funding, excessive time for the assessment, and limited wheelchair options were limitations in the assessment process. End users also commented on the need to trust the practitioner as many felt that they themselves lacked the knowledge to make informed decisions. Additionally, end users stated that environmental barriers exist and wheelchair maintenance is not readily available or timely.

The other stakeholder group stated limitations consistent with both practitioners and end users. These limitations included a lack of consistent and standardized assessment processes, limited or lack of access to knowledgeable and trained practitioners, and time intensiveness of the process. Additionally, the other stakeholder group stated that there is a lack of consistency in the documentation, and the therapist may not always be involved in the assessment, both of which are limitations.

\section{Recommendations for the Wheelchair Assessment Process}

In summary, the findings regarding the strengths and limitations of the wheelchair assessment and procurement process are consistent with that of other researchers. $3-6,8,10-11,13$ The assessment and procurement process is complex and multifaceted involving complex stages. The process includes the assessment or evaluation, a review of funding, delivery and education, and follow-up or maintenance. The results of this PAR study are instructive in the various stages of the process and are presented below. The assessment/evaluation should be a standardized, comprehensive and accurate evaluation of the client's abilities, limitations, expectations, goals, and activity interest conducted by a qualified, knowledgeable team of trusted, client-centered practitioners. Specifically, the practitioner should consider the client's interest, activities, lifestyle and funding concerns. The mobility device should permit active involvement and participation, as defined by the end user, and be used in the home and in the community. The documentation supporting the need for the device should be comprehensive, completed by a qualified team of practitioners including a therapist, and completed in a timely manner. Education for practitioners should be ongoing and

(c) The Internet Journal of Allied Health Sciences and Practice, 2013 
include all aspects of the assessment and procurement process, including funding, and education for assisting the end user to be an active, informed participant in the assessment process.

Education may also be directed specifically to the end user. In order to do this, it may be helpful to identify improved methods of education for end users regarding the specific options of wheelchair technology. The end user may also find it instructive to review videos of various wheelchairs as part of the wheelchair assessment and procurement process. Such educational materials should be readily available at rehabilitation centers, online, and in the waiting rooms of wheelchair assessment clinics. Finally, advocates for wheelchair users should collaborate to identify needs and possible solutions for education. While some of these may already exist, according to the findings of this study, the educational needs of the end user continue to be unmet.

\section{Essential Elements of a Wheelchair Assessment}

Forty-eight of the original group of on-line practitioners (81\%) contributed to the initial list of essential elements for the Delphi Study. The participants were asked to submit what they believed were essential items to be included in all wheelchair assessments. Many of the participants sent their assessment forms; others sent a list attached to the e-mail, while others simply listed the items within the electronic mail exchange. The responses were coded using Nvivo 8 software to create themes of assessment topics. The comprehensive list, which ultimately included a total of 105 items, was compiled and returned to the practitioners. They were asked to determine if they thought each item was "essential in all evaluations," "necessary at times," or "not relevant". Fifty-two (88\%) of the practitioners responded to this round of data collection of the Delphi study. An item is considered essential if it $75 \%$ or more of the participants agreed that the item was essential. Table 1 represents the "essential elements" of a wheelchair assessment as identified by practitioners.

Table 1. Essential Elements Identified by Practitioners

\begin{tabular}{|l|l|}
\hline & $\%$ Agreement \\
\hline Anticipated goals and expected outcomes & 100 \\
\hline Evaluation completed by therapist & 98 \\
\hline Posture & 98 \\
\hline Sensation & 98 \\
\hline How the chair is used (e.g., distance, indoor / outdoor) & 98 \\
\hline Equipment recommendation & 98 \\
\hline Assessment and findings & 98 \\
\hline Recommendation and plan & 98 \\
\hline Current mobility equipment & 96 \\
\hline Problems with current equip & 96 \\
\hline Medical information & 96 \\
\hline Postural mobility & 96 \\
\hline Transfers & 96 \\
\hline Power control functions & 96 \\
\hline Presenting problems & 94 \\
\hline Client or caregiver goals & 94 \\
\hline Environment (measurements and general information) & 94 \\
\hline Transportation (needs and modes) & 94 \\
\hline Precautions & 94 \\
\hline Alignment & 94 \\
\hline Ambulation & 94 \\
\hline Wheelchair skills & 94 \\
\hline Insurance or funding & 93 \\
\hline Clinical goals (pressure distribution) & 93 \\
\hline Client dimensions (height, weight, linear measurements) & 93 \\
\hline Balance & 93 \\
\hline
\end{tabular}




\begin{tabular}{|c|c|}
\hline Range of motion & 93 \\
\hline Skin integrity (previous pressure ulcer) & 93 \\
\hline Education for client / caregiver & 93 \\
\hline Diagnosis and ICD 9 & 91 \\
\hline Demographic information & 91 \\
\hline Provide education to allow informed decision & 91 \\
\hline Secondary medical diagnosis & 91 \\
\hline Motor control & 91 \\
\hline Sitting tolerance & 91 \\
\hline Type of transfer equipment & 91 \\
\hline Functional skills & 90 \\
\hline Need knowledgeable therapist & 90 \\
\hline Team members & 89 \\
\hline Supplier & 89 \\
\hline Client report of other issues & 89 \\
\hline Edema & 89 \\
\hline Hamstring flexibility & 87 \\
\hline Pain & 89 \\
\hline Fitting and adjustments & 89 \\
\hline Need knowledgeable supplier & 89 \\
\hline Reason for referral & 87 \\
\hline Previous equipment tried & 87 \\
\hline Strength & 87 \\
\hline Propulsion & 87 \\
\hline What support systems are in place & 87 \\
\hline Other expectations (light weight for transport) & 85 \\
\hline Who does client live with & 85 \\
\hline Ability to perform pressure relief and skin inspection & 85 \\
\hline Cognition, behavior, perception & 83 \\
\hline Hrs per day in w/c & 83 \\
\hline Ambulation equipment & 81 \\
\hline ADLS & 81 \\
\hline Cardio-pulmonary status & 78 \\
\hline IADLS & 77 \\
\hline Follow up after delivery & 77 \\
\hline Length of need & 76 \\
\hline Tone & 76 \\
\hline Visual skills & 76 \\
\hline Bowel and bladder status & 76 \\
\hline Communication & 76 \\
\hline
\end{tabular}

Note. $N=52$ 
Table 2. Items Not Considered Essential by Practitioners

\begin{tabular}{|c|c|}
\hline & $\%$ of agreement \\
\hline Other AT devices & 74 \\
\hline Trial use of equipment and documentation of same & 74 \\
\hline Work environment & 72 \\
\hline Surgeries and hospitalizations & 72 \\
\hline Endurance & 72 \\
\hline School environment (specifically) & 70 \\
\hline Risks of falls & 68 \\
\hline Tone intervention & 68 \\
\hline Weight bearing & 70 \\
\hline Date of onset & 69 \\
\hline Attention / concentration & 68 \\
\hline Orthotics & 66 \\
\hline Sensory processing & 66 \\
\hline AAC & 62 \\
\hline Specific respiratory status & 62 \\
\hline Mat evaluation & 62 \\
\hline Appearance of the wheelchair & 60 \\
\hline Confined to bed? & 60 \\
\hline Options if not funded & 59 \\
\hline Client's leisure interest & 59 \\
\hline Primary therapist (referring therapist) & 57 \\
\hline Observe interaction with involved parties & 57 \\
\hline Medications & 57 \\
\hline Referring MD & 53 \\
\hline Reflexes & 51 \\
\hline Hearing & 45 \\
\hline Speech skills / social skills & 43 \\
\hline Current or past therapy & 43 \\
\hline Other assessments (wheelchair skills test) & 40 \\
\hline Education for primary therapist & 40 \\
\hline Swallowing & 38 \\
\hline Input from other therapists & 34 \\
\hline Mobility algorithm & 30 \\
\hline Who brought client to clinic & 25 \\
\hline Other assessments (not pressure mapping; i.e. FEW) & 21 \\
\hline Pressure mapping done & 8 \\
\hline
\end{tabular}

Table 2 lists the items that the practitioners did not consider essential, or the items that fell below the $75 \%$ level of agreement.

$N=52$ 
End users who participated in the online discussions and focus groups were asked to list items they considered to be essential in a wheelchair evaluation. The lists were consolidated and coded in Nvivo 8, then sent to the 12 end users who participated in the online discussion. Seven or $58 \%$ of the end users responded, which represents $34 \%$ of the total end user group. Table 3 displays the rank order for all of the items from the original list of essential items as indicated by end users. As noted, the end users' items are quite different than those of the practitioners, and essentials from both groups should not be compared to each other.

\section{Table 3. Essential Elements Ranked by End Users}

\begin{tabular}{|c|c|}
\hline & $\%$ agreemen \\
\hline How does the chair fit me? & 100 \\
\hline The therapist knows what they are talking about. & 100 \\
\hline The supplier knows what they are talking about. & 100 \\
\hline Use a client-centered approach-you consider my needs. & 100 \\
\hline I need to know how to transport the chair (car, bus, and planes). & 100 \\
\hline Take accurate measurements. & 100 \\
\hline Look at my posture. & 100 \\
\hline Determine my comfort or ask how it feels to me. & 100 \\
\hline Does it meet a specific need that I identify? & 100 \\
\hline Tell me about safety. & 86 \\
\hline Can I trust the practitioners? & 86 \\
\hline I want to know about maintenance of the wheelchair. & 86 \\
\hline Give me a choice. & 86 \\
\hline Give me the authority to make a decision. & 86 \\
\hline You need to know about my disability. & 86 \\
\hline You need to consider my environment. & 86 \\
\hline Tell me about the specific components of the chair. & 86 \\
\hline Will it improve my life? & 71 \\
\hline How often do I use the wheelchair? & 71 \\
\hline Provide me with education. & 71 \\
\hline Determine how much time I spend in my wheelchair. & 71 \\
\hline I need to consider funding. & 71 \\
\hline Ask if I use other devices. & 57 \\
\hline I care what the chair looks like. & 57 \\
\hline Ask me what I can do in terms of self-care skills. & 57 \\
\hline Ask me what I like to do for leisure. & 57 \\
\hline I relied on others to tell me what I needed. & 43 \\
\hline My image is important. & 43 \\
\hline I want to use the chair for a while before I decide what I want. & 29 \\
\hline You need to examine my work environment. & 29 \\
\hline I should have a pressure map study done. & 14 \\
\hline
\end{tabular}

Note. $N=7$ 
The stakeholders were asked to indicate the essential elements of wheelchair assessments. Because the sample size was small and the data were collected in phone interviews with some stakeholders, the percentage of agreement was not sought. Table 4 displays the results of the essential elements from the stakeholder group. These are arranged in order of the process of the assessment beginning with client intake information as determined by this author.

\section{Table 4. Essential Elements Identified by Other Stakeholders}

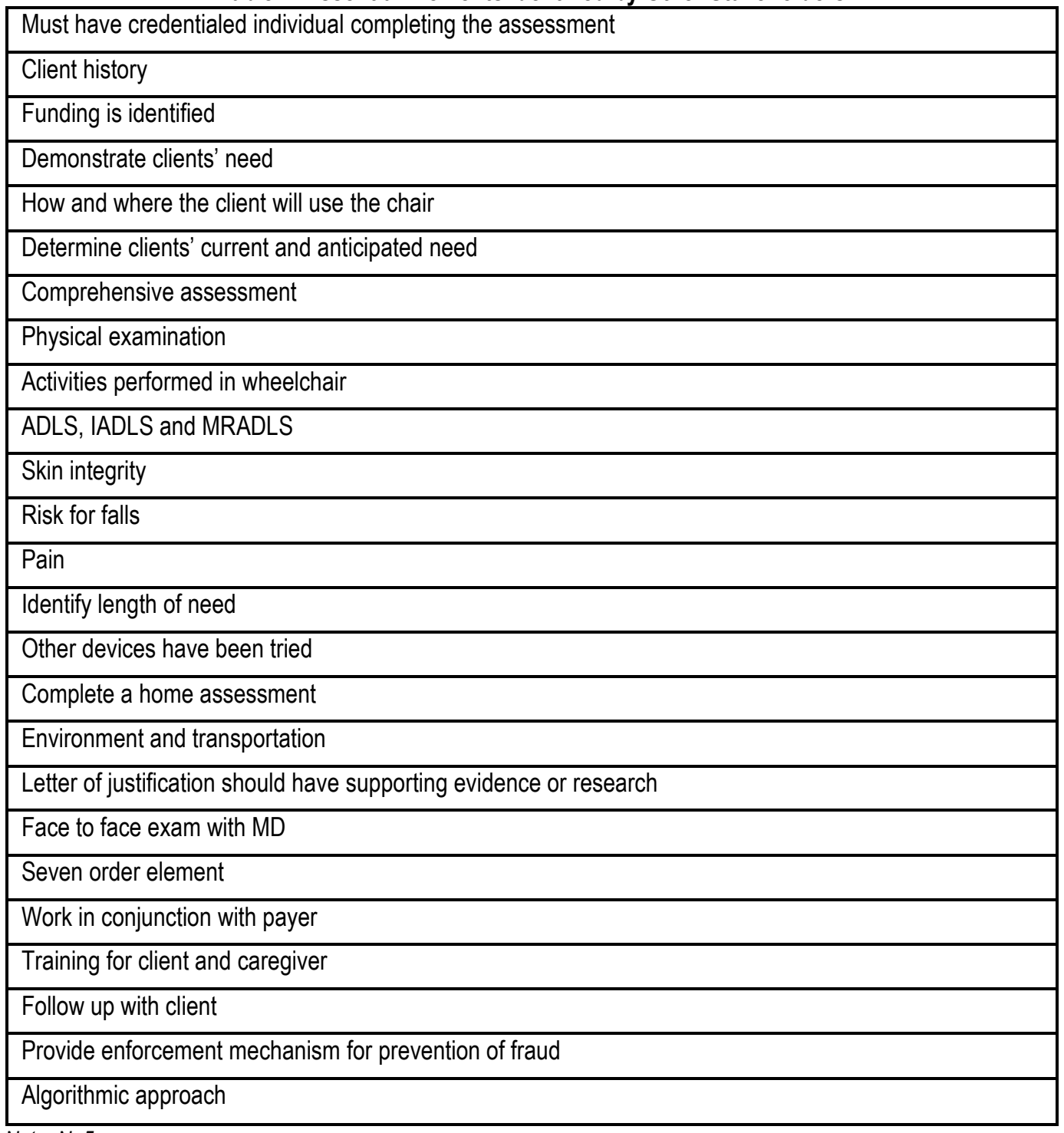

Note. $N=5$

\section{SUMMARY OF RESULTS}

A total of 155 individuals contributed to the data collection, identifying the strengths, limitations, and essential elements of wheelchair assessment, and the procurement process. Data were collected using surveys, questionnaires, document reviews, telephone interviews, and focus groups, and the data collection process spanned 11 months. The participants represented at least 21 states and Australia. Data were coded using Nvivo 8 software to establish themes and create lists. Two sets of the data were analyzed twice and an expert coder hired by the author of this study examined the second set. This was done to improve the consistency in data analysis and to determine the accurate use of Nvivo8 by the researcher. No significant discrepancies were found in the coding.

Based on the input from all stakeholders regarding the strengths, limitations, and essential elements of the wheelchair assessment, a standardized assessment is necessary. To this end, this study offers an assessment checklist that incorporates 
the input from the participants, reflects a comprehensive review of the literature, and embraces a client-centered practice. Using the ICF as the taxonomy, the essential elements identified by the various groups in this study, and a review of the literature regarding wheelchair assessments, a checklist was developed to guide the wheelchair assessment (See Table 5).36,37

\section{Table 5. A Wheelchair Assessment Checklist}

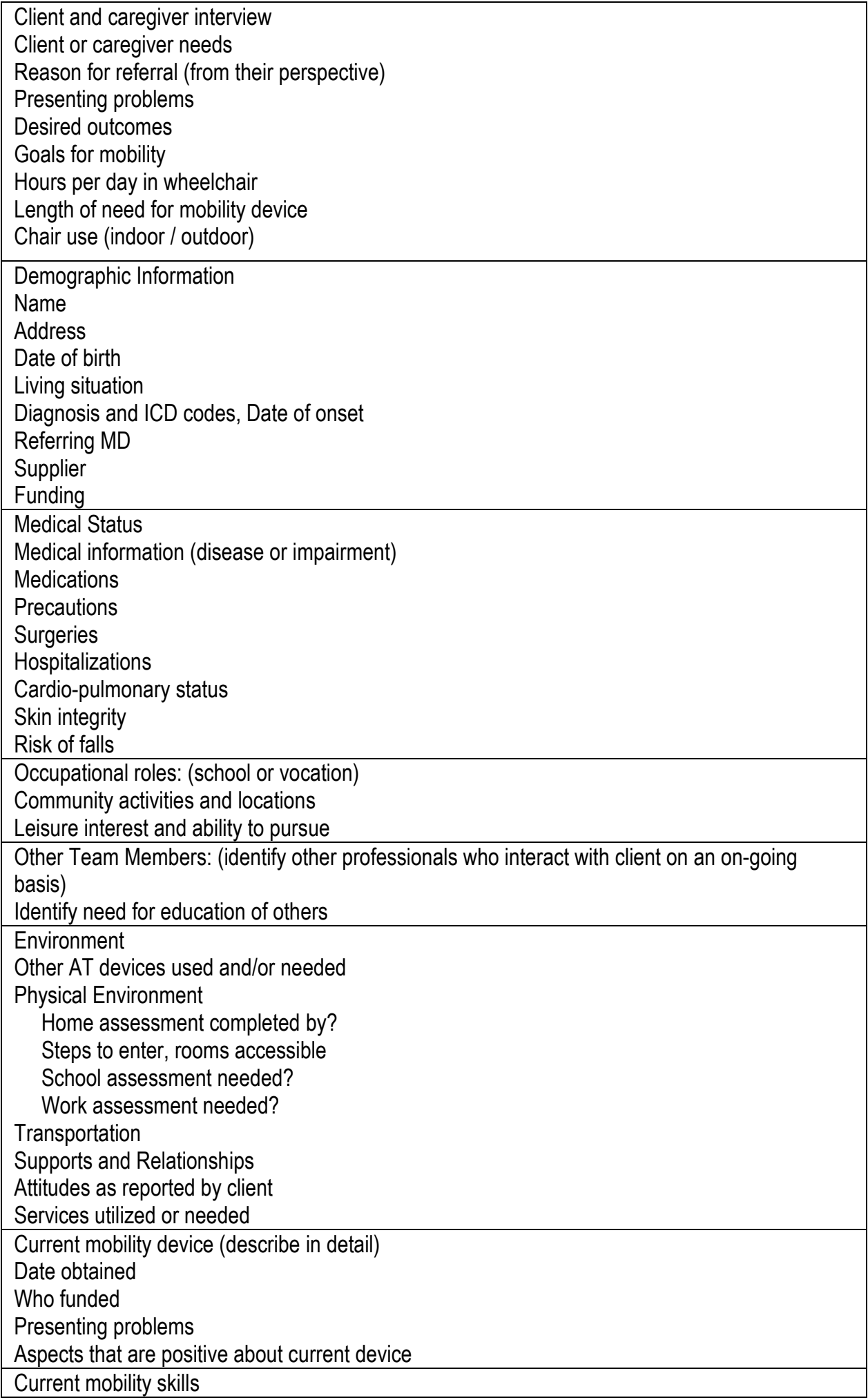




\begin{tabular}{|l|}
\hline Ambulation (devices used) \\
Lifting and carrying \\
Ability to propel manual wheelchair \\
Ability to utilize power mobility device \\
Modes of transportation used \\
Driving \\
\hline Functional Skills \\
ADLS \\
$\quad$ Grooming \\
$\quad$ Hygiene \\
Dressing \\
Bathing \\
Bowel and bladder function \\
IADLS \\
Shopping \\
Home management \\
Child care \\
Transfers and equipment used \\
Wheelchair skills (propulsion or power mobility, pressure relief) \\
Communication skills and needs \\
\hline Mat evaluation by therapist \\
Linear measurements \\
Posture \\
Range of motion \\
Motor control \\
Strength and endurance \\
Balance \\
Edema \\
Sensation, pain, skin integrity, ability to weight shift (pressure mapping as needed) \\
For power wheelchair evaluation \\
Vision, cognition, perception, behavior, attention, concentration \\
For clients with neurological issues \\
Vision, cognition, behavior, perception \\
Reflexes \\
Tone \\
Tone intervention \\
\hline Trial use of equipment \\
What was tried, why did it not meet the need \\
(Mobility algorithm as needed) \\
\hline Assessment of findings \\
Equipment recommendation \\
Equipment justification \\
Options if not funded \\
\hline Plan of Care \\
Education \\
Fitting, training and delivery \\
Follow up \\
\hline
\end{tabular}

\section{LIMITATIONS OF THE STUDY}

A limitation of the Delphi and PAR methodology utilized in this study is the iterative process of on-going data collection. In this study, data were collected over an eleven-month period. A noted limitation of this method is attrition of the participants. ${ }^{30} \mathrm{In}$ this study, the level of commitment from the practitioners ranged from a $63 \%$ to $81 \%$ response rate on the various phases of data collection. More problematic was the attrition of end users. While they identified an interest in participating, many failed to return signed consent forms. Additionally, previous PAR projects that involved multiple stakeholders in the field of AT are few. Thus, this author generated the steps of data collection based on other PAR studies, which may not be similar in content. Each 
participant had a unique perspective on the strengths, limitations and essential elements of the wheelchair assessment and procurement process, thus contributing to a diverse and multi-factorial representation of the findings of this study.

\section{RECOMMENDATIONS FOR FURTHER RESEARCH}

Though this study solicited input from policy makers, insurers, and reviewers, their participation was limited compared to that of the other groups. Future research should garner input from this group in greater detail. It should also identify the policy stakeholders and examine their attitudes and opinions as a single entity. Perhaps such a study should involve PAR, with the facilitator being a policy stakeholder. Future research may include a review of disability policies and the process by which policies are acted upon.

Future research may also entail a study tracing the process of the wheelchair assessment to the approval and payment process. While this study attempted to determine the state of practice in the wheelchair assessment and procurement process, it is beyond the scope of this work to expand upon the funding and policy processes.

Future research could also include focus groups, assembling all stakeholders in a single location to facilitate dialogue among the participants. Such focus groups should occur in multiple geographic locations to obtain input from a diverse group of individuals. Because PAR research aims to provide opportunities for distinct groups of people to engage in a consensual approach to inquiry, such an approach may be useful to conduct focus groups of stakeholders. PAR links groups of people who are potentially in conflict in an effort to attain a viable, sustainable, and effective solution to the problems that they identify. ${ }^{30}$ Therefore, PAR may be a viable and effective strategy to encourage such collaboration.

Finally, the perspectives of end users are not comparable to that of practitioners as they view the assessment process as a unique episode involving their specific wheelchair assessment experience. In other words, end users may obtain a new wheelchair every 5 to 7 years or longer in some cases. Their experience and, consequently, their response to questions in this study may not reflect the ongoing and recurrent wheelchair assessment. Their comments and opinions would be better gathered using a purely qualitative method to allow for elaboration of thoughts rather than answering close-ended questions. Specifically, future research could examine collaboration with wheelchair users and confirm whether the assessment and procurement process accurately addresses their concerns. End users have a unique perspective of the wheelchair assessment, and that perspective is perhaps based on several factors, including the relationship they have with the practitioner or supplier, the number of wheelchair assessments they have experienced, and the diagnosis and date of onset. Thus, the complexity of the variables that influence end users should be examined in greater detail, and future research should be directed to an in-depth study of end users' perceptions of the wheelchair assessment and procurement process. Because end users may not have access to the Internet, or have communication difficulties, and sometimes rely on caregivers to express their concerns, future research could be conducted that allows multiple means of data collection, including but not limited to, focus groups, individual interviews, and telephone interviews.

\section{ACKNOWLEDGEMENT}

This work would not have been possible without the guidance of my dissertation committee Dr. Max Ito, Dr. Ferol Ludwig and Dr. Frances Harris.

\section{REFERENCES}

1. LaPlante M, Kaye HS. Demographics and trends in wheeled mobility equipment use and accessibility in the community. Assistive Technology. 2010;22:3-17. [PMID: 20402043]

2. Finlayson $\mathrm{M}$, Hammel J. Providing alternative financing for assistive technology: Outcomes over twenty months. Journal of Disability Policy Studies. 2003:14:109-18.

3. Mills T, Holm M, Schmeler M. Test-Retest Reliability and Cross Validation of the Functioning Everyday with a Wheelchair instrument. Assistive Technology. 2007;19:61-77. [PMID: 17727074]

4. Cohen L. Research priorities: Wheeled mobility. Disability and Rehabilitation: Assistive Technology. 2007;2(3):173-180. [PMID: 19266636]

5. Geyer M, Brienza D, Bertocci G, Crane B, Hobson D, Karg P, et al. Wheelchair seating: A state of science report. Assistive Technology. 2003;15:120-8. [PMID: 15137729]

6. Hammel J, Finlayson M. Assistive technology access and financing: Introduction to the special series on examining the intersections of practice, research and policy. Journal of Disability Policy Studies. 2003;14:66-7.

7. Mills T, Holm M, Schmeler M. Test-retest reliability and cross validation of the functioning everyday with a wheelchair instrument. Assistive Technology. 2007;19:61-77. [PMID: 17727074]

8. Scherer M, Glueckauf R. Assessing the benefits of assistive technology for activities and participation. Rehabilitation 
Psychology. 2005;50(2):132-41.

9. Sprigle S. State of the science on wheeled mobility and seating measuring the health, activity and participation of wheelchair users. Disability and Rehabilitation: Assistive Technology. 2007;2(3):133-5. [PMID: 19266632]

10. Mortenson WB, Miller WC. The wheelchair procurement process: Perspectives of clients and prescribers. Canadian Journal of Occupational Therapy. 2008;75:167-75. [PMID: 18615928]

11. Mortenson WB, Miller WC, Miller-Polgar J. Measuring wheelchair intervention outcomes: Development of the wheelchair outcome measure. Disability Rehabilitation Assistive Technology. 2007;2:275-85. [PMID: 19263533]

12. Wressle E, Samuelsson K. User satisfaction with mobility devices. Scandinavian Journal of Occupational Therapy. 2004;11:143-50.

13. Lenker J, Paquet V. A new conceptual model for assistive technology outcomes research and practice. Assistive Technology. 2003;16:1-4. [PMID: 15357144]

14. Carey A, DelSordo V, Goldman A. Assistive technology for all: Access to alternative financing for minority populations. Journal of Disability Policy Studies. 2004;14:194-203.

15. Scherer M. Living in the state of stuck: How technology impacts lives of people with disabilities. 1993. Cambridge, MA: Brookline Books.

16. Hammel J, Finlayson M, Lastowski S. Using participatory action research to examine outcomes and effect systems change to assistive technology financing. Journal of Disability Policy Studies. 2003;14:98-108.

17. LaPlante M, Hendershot G, Moss A. Centers for Disease Control and Prevention. Assistive technology devices and home accessibility features: Prevalence, payment, need and trends. Advance Data 1997(1992). (No. 217). Retrieved from http://www.cdc.gov. Accessed May 13, 2013.

18. Rubin R, White-Means S. Race, disability and assistive devices: Sociodemographics or discrimination? International Journal of Social Economics. 2001;10:927-41.

19. Hammell K. Reflections on a disability methodology for the client-centered practice of occupational therapy research. Canadian Journal of Occupational Therapy. 2007;5:365-9. [PMID: 18183771]

20. Gray D, Quatrano I, Lieberman M. Conclusions: Moving to the next stage of assistive technology development. In Gray D, Quatrano L, Lieberman M (Eds.), Designing and using assistive technology: The human perspective, 1998, p299-310. Baltimore, MD: Brookes.

21. National Council on Disability. Federal policy barriers to assistive technology. (2000). Washington, DC: Author. Retrieved from. http://www.ncd.gov/newsroom/publications/2000/assisttechnology.htm. Accessed May 13, 2013.

22. Devitt $R$, Chau $B$, Jutai J. The effect of wheelchair use on the quality of life with persons with multiple sclerosis. Occupational Therapy in Health Care. 2003;17:63-79.

23. Day H, Jutai J. Measuring the psychosocial impact of assistive devices: The PIADS. Canadian Journal of Rehabilitation. 1996;9(2):159-68.

24. Day H, Jutai J, Campbell KA. Development of a scale to measure the psychosocial impact of assistive devices: Lessons learned and the road ahead. Disability and Rehabilitation. 2002;24(1/2/3):31-7. [PMID: 11827152]

25. Hunt PC, Boninger ML, Cooper RA, Zafonte RD, Fitzgerald SG, Schmeler MR. Demographic and socioeconomic factors associated with disparity in wheelchair customizability among people with spinal cord injury. Archives of Physical Medicine and Rehabilitation. 2004;85:1859-64. [PMID: 15520982]

26. Lutz B, Bowers B. Disability in everyday life. Qualitative Health Research. 2005;15:1037-54. [PMID:16221878]

27. Angelo J, Bunning ME, Schmeler M, Doster S. Identifying best practice in the occupational therapy assistive technology evaluation: An analysis of three focus groups. American Journal of Occupational Therapy. 1997;51(10):916-20. [PMID: 9394152]

28. Isaacson M. Best practices by occupational and physical therapists performing seating and mobility evaluations. 2003. Available from ProQuest Dissertations and Theses database. (UMI No. 3105770)

29. Dickens L, Watkins K. Action research: Rethinking Lewin. Management Learning. 1999;30(2):127-140.

30. Stringer E. Action research (3ed.). 2007. Thousand Oaks, CA: Sage Publications.

31. Ludwig B. Predicting the future: Have you considered using the Delphi methodology? Journal of Extension. 1997;35. Retrieved from http://www.joe.org/joe/1997october/tt2.html. Accessed May 13, 2013.

32. Duncan $E$. The nature and use of consensus building methodology in practice. In Kielhofner $G$ (Ed.), Research in occupational therapy: Methods of inquiry for enhancing practice. 2006, p. 401-10. Philadelphia, PA: F. A. Davis.

33. Slocum N. Participatory Methods Toolkit: A practitioner's manual. 2005. Retrieved from http/l:www.viwta.be/files/handbook.pdf. Accessed May 13, 2013.

34. Kemmis S, Taggart R. Participatory action research: Communication and the public sphere. In Denzin N, Lincoln Y, (Eds.), The Sage handbook of qualitative research. 2005(3 ${ }^{\text {rd }}$ ed), p. 559-603. Thousand Oaks, CA: Sage Publications. 
35. QSR International Products. (n.d.). Nvivo. Retrieved from http://www.qsrinternational.com/products nvivo.aspx. Accessed May 13, 2013.

36. World Health Organization. International classification of functioning, disability and health. 2001. Geneva, Switzerland: Author. Retrieved from http://www.who.int/classifications/icf. Accessed May 13, 2013.

37. World Health Organization. Towards a common language for functioning, disability, and health: ICF. 2002. Retrieved from http://www.who.int/classifications/icf/training/icfbeginnersguide.pdf. Accessed May 13, 2013.

\section{KEY TERMS}

People with Disabilities, Wheelchair Assessment; Wheelchair Procurement, Participatory Action Research and Client-Centered

Practice 